\title{
Histopathological patterns of Neoplastic gingival lesions: A six year study
}

\author{
Dr. Alpana Banerjee, $\mathrm{MD}^{1}$,Dr. Kulashekhar Bhattacharjee,MD ${ }^{2}$. \\ ${ }^{1,2}$ Assistant Professor, Department Of Pathology, Agartala Govt. Medical College And Govind Ballabh Pant \\ Hospital, Agartala, Tripura, India.
}

\begin{abstract}
Gingiva including the jaw bones (maxilla and mandible) is a site for multitude of neoplastic conditions. Traditionally histopathological examination of a tissue biopsy of the suspicious lesion is regarded as the gold standard in diagnosing these lesions. The study was a 6 year retrospective analysis carried out from January 2011 to December 2016 in the Department of Pathology, Agartala Govt. Medical College and Govind Ballabh Pant Hospital. Out of 63 neoplastic gingival lesions 25 (39.68\%) were benign, 3 (4.76\%) were premalignant and 35 (55.56\%) were malignant. Benign lesions were common in 11-30 years age group, premalignant lesions in 31-50 years age and malignant lesions were commonly seen after 60 years of age. Overall mandible (56 cases) was more commonly affected than maxilla (7 cases). In this study majority of malignant cases were squamous cell carcinoma (91.43\%), followed by one case each of verrucous carcinoma, Ewing sarcoma and ameloblastic carcinoma. Benign lesions were classified as dentigerous cyst (36\%), radicular cyst (20\%), hemangioma (20\%), fibrous dysplasia (8\%), squamous papilloma (4\%), calcifying odontogenic tumor (4\%), peripheral odontogenic fibroma (4\%) and aneurysmal bone cyst (4\%). Overall male predominance was noted. As premalignant lesions one case of squamous papilloma with severe dysplasia was reported in a male patient and two females were diagnosed with ameloblastoma.

In our study, an attempt has been made to study the histopathological patterns and age, gender and site wise distribution of various neoplastic gingival lesions reported in our institute and to compare the results with reports from other parts of the world. Based on Indian literature survey to date, we are herewith reporting the first time study of this nature from our state.
\end{abstract}

Keywords: Neoplastic gingival lesions, histopathology, dentigerous cyst, squamous cell carcinoma.

\section{Introduction}

Gingiva including the jaw bones (maxilla and mandible) is a site for multitude of neoplastic conditions [1]. Because jaws are composed of many different types of tissues, such as bone, muscle, epithelium and odontogenic tissue, they are more susceptible to developing abnormal growths than other parts of the body. Hence odontogenic cysts and tumors, squamous papilloma, epitheial malignancies commonly squamous cell carcinoma, bone tumors and other mesenchymal neoplasms are commonly encountered in this part of the body. Clinical findings and radiological features are many a time inconclusive to give a definitive diagnosis. Traditionally histopathological examination of a tissue biopsy of the suspicious lesion is regarded as the gold standard.

An accurate comparison and evaluation of the findings obtained by previous epidemiological studies is difficult because of the limited number of reported cases; this is the reason why estimating the prevalence of gingival lesions world-wide proves to be an arduous task. Very few studies have been reported from Asia, particularly from Indian subcontinent $[2,3]$. The aim of this study was that of analyzing histopathological patterns of neoplastic gingival lesions and age and gender wise distribution of cases in Tripura, a North Eastern state of India.

\section{Material and Methods}

This was a 6 year retrospective study carried out from January 2011 to December 2016. All the gingival biopsy specimens received in the Department of Pathology, Agartala Govt. Medical College and Govind Ballabh Pant Hospital during that period were included in the study. Data such as age, gender and site of the lesion were collected from the records. All the slides were retrieved from archive and reviewed by both the authors. Restaining of the slides with hematoxylin and eosin (Hand E) was performed whenever required. Data collected were analyzed.

\section{Results}

A total number of 63 gingival lesions were included in the study, out of which 25 (39.68\%) were benign, 3 (4.76\%) were premalignant and $35(55.56 \%)$ were malignant. Age ranged from 8 years to 85 years. 
Benign lesions were common in 11-30 years age group, premalignant lesions in 31-50 years age and malignant lesions were commonly seen after 60 years of age. Malignancies were rare before 20 years except one case of Ewing sarcoma diagnosed in a 12 years old boy (Table 1). Overall mandible (56 cases) was more commonly affected than maxilla (7 cases).

Benign lesions were classified as dentigerous cyst (36\%), radicular cyst (20\%), hemangioma $(20 \%)$, fibrous dysplasia (8\%), squamous papilloma (4\%), calcifying odontogenic tumor (4\%), peripheral odontogenic fibroma (4\%) and aneurysmal bone cyst (4\%). Male preponderance was noted. Mandible was more commonly affected than maxilla by benign tumors and cysts. As premalignant lesions one case of squamous papilloma with severe dysplasia was reported in a male patient and two females were diagnosed with ameloblastoma (Figure 1). Both the lesions involved the mandible. Malignant lesions accounted for $55.56 \%$ of all gingival neoplastic lesions. Thirty two out of 35 malignant tumors were diagnosed as squamous cell carcinoma (91.43\%) with M:F $=1.29: 1$, one resulted to be verrucous carcinoma $(2.86 \%)$ in a male patient, one as Ewing sarcoma $(2.86 \%)$ in a 12 years old boy and one was ameloblastic carcinoma in a male subject comprising $2.86 \%$ of all malignant cases (Figure 2). All the malignant lesions affected mandible except one case of squamous cell carcinoma that had involved maxilla (Table 2).

Table 1: Age distribution of gingival tumors.

\begin{tabular}{|c|c|c|c|c|}
\hline Age (years) & Benign & Premalignant & Malignant & Total \\
\hline $0-10$ & 1 & - & - & $1(1.59 \%)$ \\
\hline $11-20$ & $\mathbf{7}$ & - & 1 & $8(12.70 \%)$ \\
\hline $21-30$ & $\mathbf{7}$ & - & 2 & $9(14.28 \%)$ \\
\hline $31-40$ & 3 & $\mathbf{2}$ & 3 & $8(12.70 \%)$ \\
\hline $41-50$ & 1 & $\mathbf{1}$ & 5 & $7(11.11 \%)$ \\
\hline $51-60$ & 5 & - & 7 & $\mathbf{1 2}(\mathbf{1 9 . 0 5 \% )}$ \\
\hline $61-70$ & 1 & - & $\mathbf{9}$ & $\mathbf{1 0}(\mathbf{1 5 . 8 7 \%})$ \\
\hline$>70$ & - & - & $\mathbf{8}$ & $8(12.70 \%)$ \\
\hline Total & $\begin{array}{l}\mathbf{2 5} \\
(\mathbf{3 9 . 6 8} \%)\end{array}$ & $\mathbf{3}(\mathbf{4 . 7 6 \% )}$ & $\begin{array}{l}\mathbf{3 5} \\
(\mathbf{5 5 . 5 6 \%})\end{array}$ & $\mathbf{6 3}(\mathbf{1 0 0 \% )}$ \\
\hline
\end{tabular}

Table 2: Gender and site distribution of various neoplastic gingival tumors.

\begin{tabular}{|c|c|c|c|c|}
\hline Type & No & M:F & Mandible & Maxilla \\
\hline \multicolumn{5}{|l|}{ Benign } \\
\hline Dentigerous cyst & $9(36 \%)$ & $1.25: 1$ & 5 & 4 \\
\hline Radicular cyst & $5(20 \%)$ & $1.5: 1$ & 4 & 1 \\
\hline Hemangioma & $5(20 \%)$ & $4: 1$ & 4 & 1 \\
\hline Fibrous dysplasia & $2(8 \%)$ & $1: 1$ & 2 & - \\
\hline $\begin{array}{l}\text { Squamous } \\
\text { papilloma }\end{array}$ & $1(4 \%)$ & All female & 1 & - \\
\hline $\begin{array}{c}\text { Calcifying } \\
\text { odontogenic } \\
\text { Tumor }\end{array}$ & $1(4 \%)$ & All female & 1 & - \\
\hline $\begin{array}{c}\text { Peripheral } \\
\text { odontogenic } \\
\text { Fibroma }\end{array}$ & $1(4 \%)$ & All male & 1 & - \\
\hline $\begin{array}{l}\text { Aneurysmal bone } \\
\text { cyst }\end{array}$ & $1(4 \%)$ & All male & 1 & - \\
\hline \multicolumn{5}{|l|}{ Premalignant } \\
\hline $\begin{array}{c}\text { Squamous } \\
\text { papilloma with } \\
\text { Severe dysplasia }\end{array}$ & $(33.33 \%)^{1}$ & All male & 1 & - \\
\hline Ameloblastoma & $\begin{array}{r}2 \\
(66.67 \%)^{2} \\
\end{array}$ & All female & 2 & - \\
\hline \multicolumn{5}{|l|}{ Malignant } \\
\hline $\begin{array}{l}\text { Squamous cell } \\
\text { carcinoma }\end{array}$ & $\begin{array}{r}32 \\
(91.43 \%)\end{array}$ & $1.29: 1$ & 31 & 1 \\
\hline
\end{tabular}


Histopathological patterns of neoplastic gingival lesions: A six year study

\begin{tabular}{|c|c|c|c|c|}
\hline $\begin{array}{c}\text { Verrucous } \\
\text { carcinoma }\end{array}$ & $1(2.86 \%)$ & All male & 1 & - \\
\hline Ewing sarcoma & $1(2.86 \%)$ & All male & 1 & - \\
\hline $\begin{array}{c}\text { Ameloblastic } \\
\text { carcinoma }\end{array}$ & $1(2.86 \%)$ & All female & 1 & \\
\hline
\end{tabular}

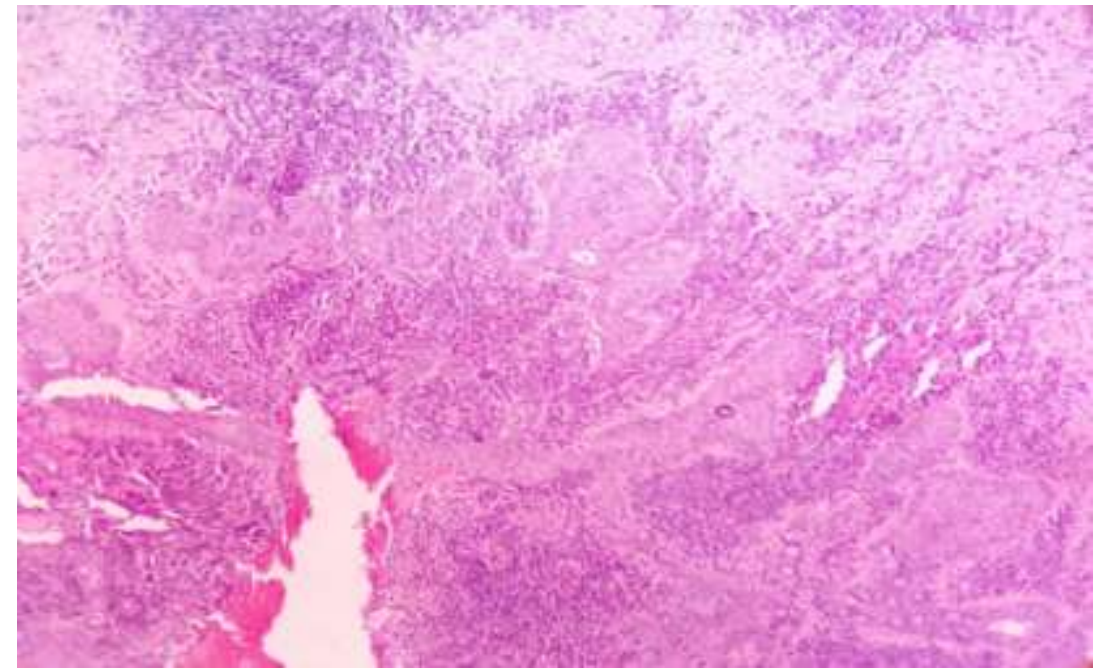

Figure 1: Microscopic picture of a case of ameloblastoma (H \& E, X 100).

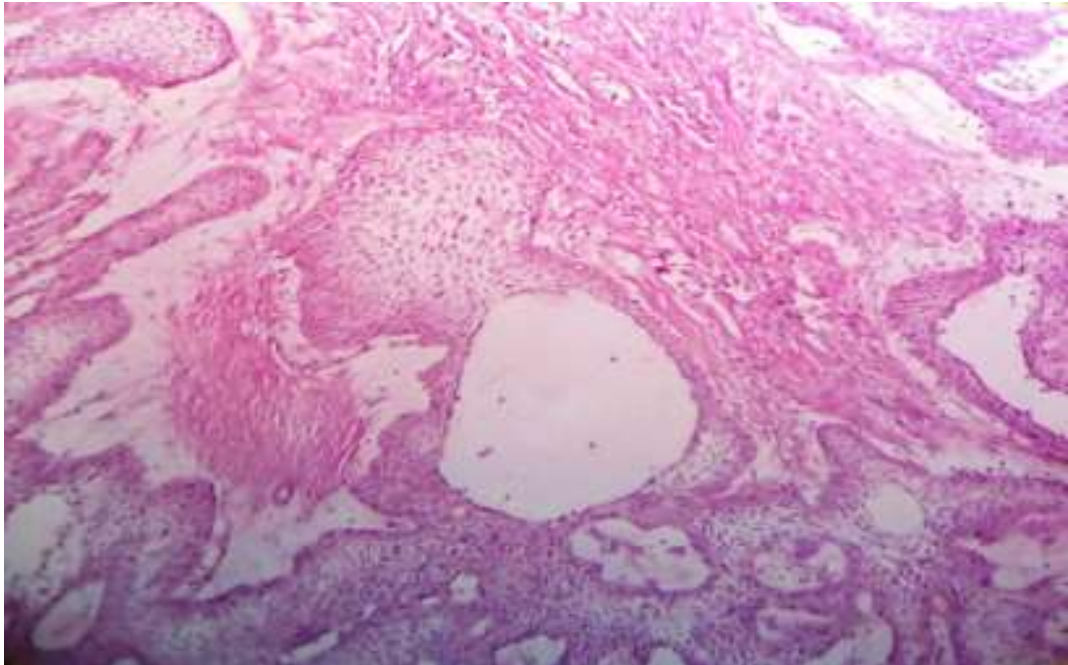

Figure 2: Microphotograph of a case of ameloblastic carcinoma (H \& E, X 100).

\section{Discussion}

Till date most of the studies reported on gingival and oral lesions are mostly from America, Europe and Africa. Very few studies have been reported from Asia, especially from the Indian subcontinent. Based on the Indian literature survey, to date, we are herewith reporting for the first time a study on gingival neoplastic lesions from our state Tripura.

Malignant neoplastic lesions represented $55.56 \%$ of all diagnosed gingival neoplastic lesions. This finding is similar to the observation of Carbone et al. (4). They had reported 43 malignant lesions and 25 benign gingival lesions. The data collected in the present study highlighted prevalence of malignant lesions in the gingiva of mandible ( 34 out of 35 cases). Similarly most of the literatures described the mandible as being the preferential location of malignant neoplasms $(5,6)$. In this study majority of malignant cases were squamous cell carcinoma $(91.43 \%)$, followed by one case each of verrucous carcinoma, Ewing sarcoma and ameloblastic carcinoma. Similarly, squamous cell carcinoma was found to prevail in many other studies $(4,5,7,8)$. Squamous cell carcinomas were more common in males with a M:F ratio of 1.29:1, similar to the findings of Modi et al. (8). This could be attributable to more unhygienic oral habits by males. In the present study one case each of 
verrucous carcinoma and Ewing sarcoma were diagnosed in males and a case of ameloblastic carcinoma was diagnosed in a female patient. Malignancies were common after 60 years of age and uncommon before 20 years. This could be attributed to their longstanding oral habits. Chen et al. (9) concluded that the incidence peak of oral squamous cell carcinoma has moved from the seventh to the eighth decade of human life as our race is surviving for longer.

In our report, premalignant lesions represented $4.76 \%$ of gingival neoplastic lesions, one case of these was squamous papilloma with severe dysplasia and 2 cases were ameloblastoma. The former was diagnosed in a 50 years old male. Carbone et al. (4) revealed that $14.8 \%$ of gingival precancerous lesions were epithelial dysplasia of different degrees. Ameloblastoma is a painless, slow growing, locally aggressive tumor. It has a peak incidence in third and fourth decade of life but can be found in any age group with equal gender predilection (10). This observation is comparable to our study. Eighty percent (80\%) of ameloblastomas occurs in the mandible (11). In our study both cases of ameloblastomas were seen in females and both affected mandible. The most common gingival benign lesion encountered was dentigerous cyst comprising $36 \%$ of cases, which is in disagreement with the study conducted by Tay (12). A greater frequency of dentigerouc cyst was found among the male gender $(\mathrm{M}: \mathrm{F}=1.25: 1)$ and mandible was the preferential site. These findings are in concurrence with Ramachandra et al. (13). In our study the radicular cyst accounted for $20 \%$ of all benign gingival lesions and prevalence among male gender was higher than the females $(\mathrm{M}: \mathrm{F}=1.5: 1)$ which is in agreement with the study conducted by Ramachandra et al. (13). Mandible was found to be commonly affected site by radicular cyst which differs from those described by Ochsenius et al. (14). Our study reported 5 cases of hemangioma $(\mathrm{M}: \mathrm{F}=4: 1)$ out of which 4 involved mandible and one case peripheral odontogenic fibroma in a male subject affecting mandible. These findings are comparable to the observations of Carbone et al. (4). We also reported one case each of squamous papilloma and calcifying odontogenic tumor. Both were in female subjects and in mandible. Two cases of fibrous dysplasia $(\mathrm{M}: \mathrm{F}=1: 1)$ affecting mandible and one male patient with aneurysmal bone cyst involving mandible were diagnosed in our study. These findings are in agreement with Saxena et al. (15).

In our study, an attempt has been made to study the histopathological patterns and age, gender and site wise distribution of various gingival lesions reported in our institute and to compare the results with reports from other parts of the world. Based on Indian literature survey to date, we are herewith reporting the first time study of this natures from our state.

\section{Conclusion}

In the present study we observed that malignant lesions were more common than benign ones in the gingiva. Suamous cell carcinoma was the commonest malignancy (91.43\%) and dentigerous cyst was the most common benign lesion (36\%). Overall male predominance was noted and mandible was more commonly affected than maxilla. Benign lesions were common in 11-30 years age group and malignant lesions were commonly seen after 60 years of age. Malignancies were rare before 20 years.

\section{Acknowledgement}

Our great gratitude to all the technicians of histopathology section, Department of Pathology, AGMC \& GBP Hospital for their invaluable support in retrieving slides from archives and taking new sections including staining whenever required. Sincere thanks are extended to laboratory attendants for helping us collecting data from the records.

\section{References}

[1]. Theodorou DJ, Theodorou SJ. Primary non-odontogenic tumors of the jaw bones: an overview of essential radiographic findings. Clin Imaging 2003; 27: 59-70.

[2]. Verkhede A, Tupkari J, Mandale M, Sadar M. Odontogenic tumors: Review of 60 cases. J Clin Exp Dent. 2010; 2: 183-6.

[3]. Gupta B, Ponniah I. The pattern of odontogenic tumors in a government teaching hospital in the southern Indian sate of Tamil Nadu. Oral Surgery, Oral Medicine, Oral Radiology and Endodontology 2010; 110(1): 32-9.

[4]. Carbone M, Broccoletti R, Gambino A, Carrozzo M, Tanteri C, Calogiuri PL, et al. Clinical and histological features of gingival lesions: A 17-year retrospective analysis in a northern Italian population. Med Oral Patol Cir Bucal 2012 Jul; 17(4):e555-61.

[5]. Ariyoshi Y, Shimahara M, Omura K, Yamamoto E. Epidemiological study of malignant tumors in the oral and maxillofacial region: survey of member institutions of the Japanese Society of Oral and Maxillofacial Surgeons, 2002. Int J Clin Oncol. 2008; 13: 220-8.

[6]. Makridis SD, Mellado JR, Freedman AL, Salkin LM, Stein MD, Leal K, et al. Squamous cell carcinoma of gingiva and edentulous alveolar ridge: a clinicopathologic study. Int J Periodontics Restorative Dent.1998;18:292-8.

[7]. Layfield LL, Shopper TP, Weir JC. A diagnostic survey of biopsied gingival lesions. J Dent Hyg. 1995; 69: 175-9.

[8]. Modi D, Laishram RS, Sharma LD, Debnath K. Pattern of oral cavity lesions in a tertiary care hospital in Manipur, India. J Med Soc 2013; 27: 199-202.

[9]. Chen JK, Katz RV, Krutchkoff DJ. Intraoral squamous cell carcinoma. Epidemiologic patterns in Connecticut from 1935 to 1985. Cancer 1990; 66: 1288-96.

[10]. Vohra FA, Hussain M, Mudassir MS. Ameloblastomas and their management: a review. Pak J Surg 2009; 14(3): 136-42.

[11]. Small IA, Waldron CA. Ameloblastoma of the jaws. Oral Surg 1955; 8: 281-97. 
[12]. Tay AB. A 5-year survey of oral biopsies in an oral surgical unit in Singapore: 1993-1997. Ann Acad Med Singapore 1999; 28: 6571.

[13]. Ramachandra S, Shekar PC, Prasad S, Kumar KK, Reddy GS, Prakash KL, et al. Prevalence of odontogenic cysts and tumors: A retrospective clinico-pathological study of 204 cases. SRM Journal of Research in Dental Sciences 2014; 5(3): 170-3.

[14]. Ochsenius G, Escobar E, Godoy L, Penafiel C. Odontogenic cysts: Analysis of 2,944 cases in Chile. Med Oral Patol Oral Cir Bucal 2007; 12: e 85-91.

[15]. Saxena S, Kumar S, Pundir S. Pediatric jaw tumors: Our experience. Journal of Oral and Maxillofacial Pathology 2012; 16(1): 2730 . 